\title{
COMPARISON OF EXPLICIT AND IMPLICIT FORMS OF THE MODIFIED POINT MASS TRAJECTORY MODEL
}

\author{
LESZEK BARANOWSKI \\ Military University of Technology, Faculty of Mechatronics and Aeropace, Warszawa, Poland \\ e-mail: leszek.baranowski@wat.edu.pl
}

BŁażej Gadomski, Jacek Szymonik

PIT-RADWAR S.A., Warszawa, Poland

e-mail: blazej.gadomski@pitradwar.com; jacek.szymonik@pitradwar.com

PRZEMYSŁAW MAJEWSKI

PIT-RADWAR S.A., Warszawa, Poland and

University of Warsaw, Chair of Mathematical Methods in Physics, Warsaw, Poland

e-mail: przemek.majewski@gmail.com

\begin{abstract}
The article compares the results of trajectory computation for a $35 \mathrm{~mm}$ projectile using two forms (explicit and implicit) of the modified point-mass trajectory model. All necessary ammunition parameters (aerodynamic coefficients, dimensions, mass etc.) and initial conditions for differential equations are provided. The results of numerical integration (using non-stiff fourth-order Runge-Kutta solver) are presented in form of projectile trajectories projections onto vertical and horizontal planes. Data tables comparing both models in terms of projectile position and velocity in chosen time steps are also attached.
\end{abstract}

Keywords: exterior ballistics, projectile motion, MPMTM, equations of motion, projectile trajectory

\section{Introduction}

One of the requirements for algorithms implemented in Fire Control Systems (e.g. probability calculation via initial condition error propagation, finding fire-control solution) is limited runtime. Some of FCS algorithms require the use of a certain model of the projectile trajectory. The basic approach to projectile trajectory calculations is to use a Modified Point-Mass Trajectory Model (MPMTM), also known as the four degree-of-freedom model or the Lieske model (after an American R. Lieske, who initiated its widespread usage), whose foundations were introduced by Lieske and Reiter (1966). One of the MPMTM implementations is presented in (STANAG 4355, 2009) and exemplary calculations based on it were published by Baranowski (2013), McCoy (1999), Coleman et al. (2003).

A significant weakness of this MPMTM representation is the iterative method for determining the yaw of repose, which makes this approach time consuming. In order to overcome this limitation, a new explicit form of the MPMTM was proposed by Baranowski et al. (2016).

The aim of this paper is to compare both implicit and explicit forms of MPMTM. The two model variations are analyzed in terms of the obtained results and runtime. Firstly, we characterize the differential equations describing motion of the projectile for both forms. We also provide initial conditions for the equations of motion as well as other necessary parameters of the mathematical model such as:

- physical parameters of the chosen $35 \mathrm{~mm}$ ammunition; 
- values of aerodynamic coefficients of the projectile;

- atmospheric conditions used in simulation tests.

Calculations of $35 \mathrm{~mm}$ projectile trajectories are conducted for standard atmospheric conditions (STANAG 4119, 2007) considering three different scenarios, i.e.:

- no wind present along the projectile trajectory;

- homogeneous cross wind introduced along the projectile trajectory;

- homogeneous tail wind introduced along the projectile trajectory.

The runtimes of integration of the projectile path for different elevation angles for both the explicit and implicit forms have been measured and later compared. In order to enhance model analysis, we have used MATLAB scripts and built-in functions.

\section{Projectile motion models}

\subsection{Modified point-mass trajectory model (MPMTM) - implicit form}

The basic MPMTM is a conventional point-mass model but, in addition, the instantaneous equilibrium yaw is calculated at each time step along the trajectory. It provides estimates of yaw and drag, lift, and Magnus force effects resulting from the yaw of repose. The assumptions made at the stage of model derivation require that the projectile is dynamically stable, only the most essential forces and moments are taken into account, transition processes in projectile oscillatory motion around its center of mass are ignored due to replacement of the total angle of attack $\alpha_{t}$ with the yaw of repose $\alpha_{e}$.

The mathematical model of artillery projectile 3D motion, according to the implicit form of the MPMTM, contains the following equations (Baranowski, 2013; Coleman et al., 2003):

- dynamic differential equation of motion of the projectile center of mass

$$
m \dot{\mathbf{u}}=\mathbf{D F}+\mathbf{L F}+\mathbf{M F}+m \mathbf{g}
$$

— dynamic equation for rotation around the projectile axis of symmetry

$$
\frac{d \mathbf{p}}{d t}=\frac{\pi \rho d^{4} v C_{\text {spin }}}{8 I_{x}} \mathbf{p}
$$

- equation of the yaw of repose vector

$$
\boldsymbol{\alpha}_{e}=-\frac{8 I_{x} p(\mathbf{v} \times \dot{\mathbf{u}})}{\pi \rho d^{3}\left(C_{M_{\alpha}}+C_{M_{\alpha^{3}}} \alpha_{e}^{2}\right) v^{4}}
$$

where DF, LF, MF, g are the drag, lift, Magnus and gravity force vector, respectively

$$
\begin{array}{lr}
\mathbf{D F}=-\frac{\pi \rho i d^{2}}{8}\left[C_{D_{0}}+C_{D_{\alpha^{2}}}\left(Q_{D} \alpha_{e}\right)^{2}\right] v \mathbf{v} & \mathbf{L F}=\frac{\pi \rho d^{2} f_{L}}{8}\left(C_{L_{\alpha}}+C_{L_{\alpha^{3}}} \alpha_{e}^{2}\right) v^{2} \boldsymbol{\alpha}_{e} \\
\mathbf{M F}=-\frac{\pi \rho d^{3} Q_{M} p C_{m a g-f}}{8}\left(\boldsymbol{\alpha}_{e} \times \mathbf{v}\right) & m \mathbf{g}=-m g\left[\begin{array}{l}
0 \\
1 \\
0
\end{array}\right]
\end{array}
$$

The meaning of letter symbols used in equations (2.1)-(2.4) is as follows: $\rho$ - density of air, $d-$ caliber of the projectile, $m$ - mass of the projectile, $v$ - velocity of the projectile with respect to the air: $v=u-w, u$ - velocity of the projectile with respect to a ground - fixed reference system, 
$w$ - velocity of the wind, $p$ - angular velocity of the spinning motion, $I_{x}$ - moment of inertia along the axis of the projectile, $C_{\text {spin }}$ - spin damping coefficient, $C_{M_{\alpha}}$ - overturning moment coefficient, $C_{M_{\alpha^{3}}}$ - cubic overturning moment coefficient, $C_{D_{0}}$ - drag force coefficient, $C_{D_{\alpha^{2}}}$-yaw drag coefficient, $C_{L_{\alpha}}$ - lift force coefficient, $C_{L_{\alpha^{3}}}$ - cubic lift force coefficient, $C_{m a g-f}$ - Magnus force coefficient, $i, f_{L}, Q_{M}, Q_{D}$ - fitting factors for the drag, lift, Magnus force and yaw drag, respectively, $g$ - gravitational acceleration.

In the above equations of motion of the projectile, the Coriolis force is neglected. In our calculations we assumed (unlike in the model described in STANAG 4355) constant gravity force along the projectile trajectory as we considered only ground firing trajectories. It is worth mentioning that we also assumed $C_{M_{\alpha^{3}}}=C_{L_{\alpha^{3}}}=0$ during the simulations (as a result of linear dependency of $C_{L}$ and $C_{M}$ on $\alpha$ ).

\subsection{Modified point-mass trajectory model - explicit form}

In the form presented in the previous Section, the vector $\boldsymbol{\alpha}_{e}$ depends on $\dot{\mathbf{u}}$, which results in a differential equation being defined by an implicit function. The derivation of the explicit MPMTM was introduced by Baranowski et al. (2016). In the equations of motion of the projectile, the Coriolis force is neglected and the gravitational force is constant. The differential equations for the final form of the explicit model are as follows:

$$
\dot{\mathbf{x}}=\mathbf{v}+\mathbf{w}
$$

where $\mathbf{x}$ is the three-dimensional position vector

$$
\begin{aligned}
& \dot{p}=\frac{\rho v^{2}}{2 I_{x}} S d C_{\text {spin }} \widehat{p} \quad S=\frac{\pi d^{2}}{4} \\
& \dot{v}=-\frac{\rho v^{2}}{2 m} S\left[C_{D 0}+\widehat{C}_{D \alpha^{2}}\left(\frac{2 m g}{\rho v^{2} S}\right)^{2} \frac{\widehat{I}_{x}^{2} \widehat{p}^{2} \cos ^{2} \gamma_{a}}{\left(1-\widehat{I}_{x} \widehat{p}^{2} \widehat{C}_{m a g-f}\right)^{2}+\left(\widehat{I}_{x} \widehat{p} \widehat{C}_{L \alpha}\right)^{2}}\right]-g \sin \gamma_{a}
\end{aligned}
$$

and $^{1}$

$$
\left[\begin{array}{c}
\dot{\gamma}_{a} \\
\dot{\chi}_{a} \cos \gamma_{a}
\end{array}\right]=-\frac{g}{v} \frac{\cos \gamma_{a}}{\left(1-\widehat{I}_{x} \widehat{p}^{2} \widehat{C}_{m a g-f}\right)^{2}+\left(\widehat{I}_{x} \widehat{p} \widehat{C}_{L \alpha}\right)^{2}}\left[\begin{array}{c}
1-\widehat{I}_{x} \widehat{p}^{2} \widehat{C}_{m a g-f} \\
\widehat{I}_{x} \widehat{p} \widehat{C}_{L \alpha}
\end{array}\right]
$$

Dimensionless coefficients used in equations are

$$
\widehat{I}_{x}=\frac{I_{x}}{m d^{2}} \quad \widehat{p}=\frac{p d}{v}
$$

The above equations describe the case in which the wind is homogeneous within the interval of integration, i.e. $\dot{\mathbf{w}}=0$. Please note, that rigorously it is not equivalent to a constant wind, merely that the wind is constant along the flight path. Nevertheless, in practice, such phenomena are almost impossible to occur in ballistics. The dimensionless coefficients are given as

$$
\widehat{C}_{D \alpha^{2}}=\frac{C_{D \alpha^{2}}}{\left(C_{M \alpha}\right)^{2}} \quad \widehat{C}_{L \alpha}=\frac{C_{L \alpha}}{C_{M \alpha}} \quad \widehat{C}_{m a g-f}=\frac{C_{m a g-f}}{C_{M \alpha}}
$$

Let us recall that from (Baranowski et al., 2016) it follows that the explicit and implicit forms of the MPMTM are equivalent.

\footnotetext{
${ }^{1} \gamma_{a}$ is the elevation angle of $\mathbf{v}$ measured from the horizontal direction, i.e. the air-path inclination angle and $\chi_{a}$ is the azimuth angle of $\mathbf{v}$, i.e. the air-path azimuth angle.
} 


\section{Physical model}

The flight simulation computer program of artillery projectiles requires determination of the socalled physical model (Koruba et al., 2010; Kowaleczko and Żyluk, 2009; Ładyżyńska-Kozdraś, 2012) which includes the following characteristics:

- geometries, mass and inertial, aerodynamic characteristics of the projectile,

- surrounding environment (density, viscosity, temperature, pressure, velocity and wind direction depending on weather, flight altitude, etc.).

$35 \mathrm{~mm}$ TP-T ammunition parameters used in the simulation tests are as follows:

- projectile mass $m=0.55 \mathrm{~kg}$,

- projectile muzzle velocity $v=1180 \mathrm{~m} / \mathrm{s}$,

- projectile calibre $d=0.035 \mathrm{~m}$,

- projectile axial moment of inertia $I_{x}=0.97 \cdot 10^{-4} \mathrm{~kg} \mathrm{~m}^{2}$.

In the process of trajectory generation, we have used aerodynamic coefficients obtained for $35 \mathrm{~mm}$ TP-T ammunition from PRODAS software (Baranowski and Furmanek, 2013). The coefficients of aerodynamic drag, lift force and spin dumping moment have been interpolated using polynomials in the following form (Pope, 1978; Shanks and Walton, 1957)

$$
C(\mathrm{Ma})=(1+s) A(r)+(1-s) B(r)
$$

where

$$
\begin{array}{ll}
A(r)=a_{0}+a_{1} r+a_{2} r^{2} & B(r)=b_{0}+b_{1} r+b_{2} r^{2} \\
s=\frac{r}{\sqrt{\left(1-L^{2}\right) r^{2}}+L^{2}} & r=\frac{\mathrm{Ma}^{2}-K^{2}}{\mathrm{Ma}^{2}+K^{2}}
\end{array}
$$

where $C(\mathrm{Ma})$ is an aerodynamic coefficient dependent on the Mach number and $a_{0}, a_{1}, a_{2}, b_{0}$, $b_{1}, b_{2}, K, L$ are parameters to be identified. Figures $1 \mathrm{a}$ and $1 \mathrm{~b}$ present aerodynamic drag and lift force coefficients in nodes and the result of polynomial interpolation with the use of polynomial (3.1). Gridded data piecewise cubic Hermite interpolation (MATLAB griddedInterpolant class) has been used to represent the induced drag and Magnus force coefficients.
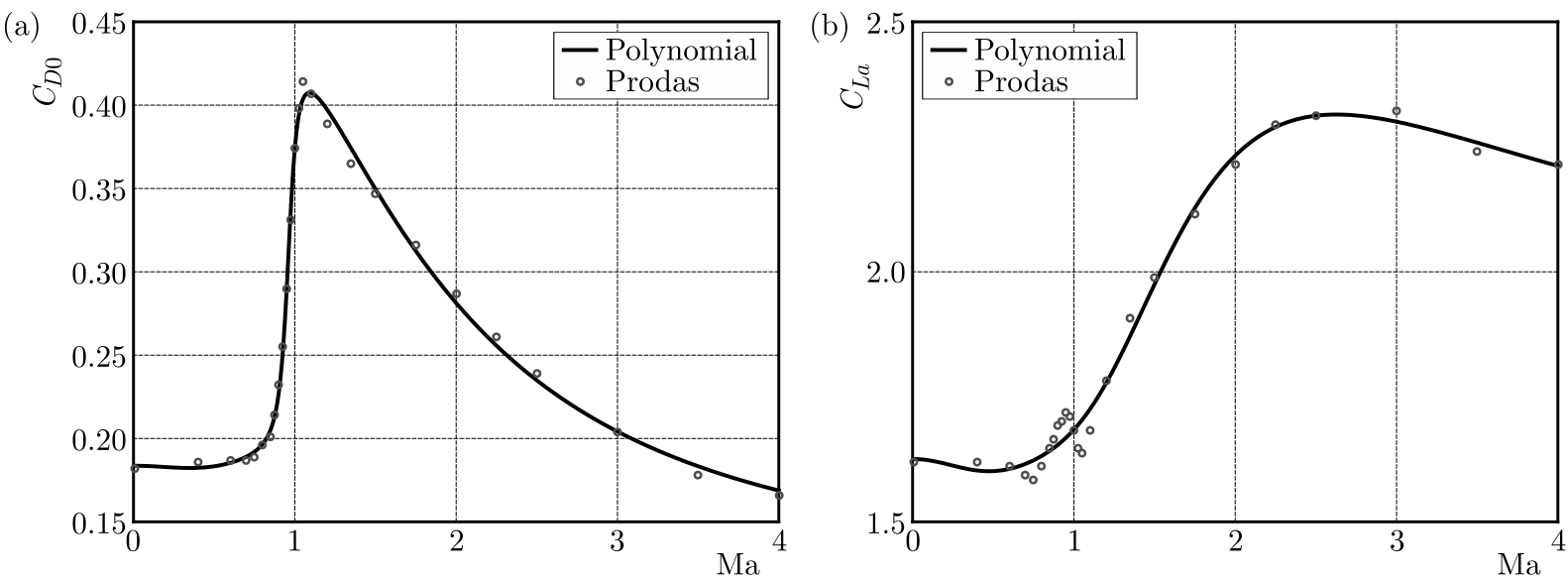

Fig. 1. Drag (a) and lift (b) force coefficient as a function of the Mach number

In order to compare explicit and implicit forms of the MPMTM, the projectile is "shot" from the origin at $[0,0,0]$ along the $x$ axis with the quadrant elevation $Q E$ equal to 710 mils - the 
angle of the maximum range for chosen $35 \mathrm{~mm}$ ammunition. The initial angular velocity of the spinning motion is calculated using

$$
p=\frac{2 \pi v}{27.57 d}
$$

where the number 27.57 reflects the length of the revolution of the rifling in caliber units. The initial time instance is obviously gauged to zero. As it was mentioned before, the gravitational force is constant along the projectile trajectory with the gravitational acceleration $g=9.80665 \mathrm{~m} / \mathrm{s}^{2}$. The flight of projectile is simulated in standard atmospheric conditions (ISO 2533, 1975) both without and with homogeneous non-zero wind.

\section{Simulation tests results}

In this Section we present and compare the results of flight simulation tests of the $35 \mathrm{~mm}$ TP-T projectile using both the implicit and the explicit form of the MPMTM. The parameters of the model and initial conditions for the differential equations of motion used are presented in Section 3. We also compare the time needed by both models to generate trajectories for different elevation angles.

\subsection{Results for standard atmospheric conditions}

Figures $2 \mathrm{a}$ and $2 \mathrm{~b}$ present trajectory projections on the vertical and horizontal plane, respectively. An assumption has been made that there is no wind within the integration interval. Based on the plotted trajectories one cannot unambiguously decide whether there are any differences between two models. In order to analyze the results in a more detailed way, differential equations of motion where have been integrated using a non-stiff fourth-order Runge-Kutta solver.
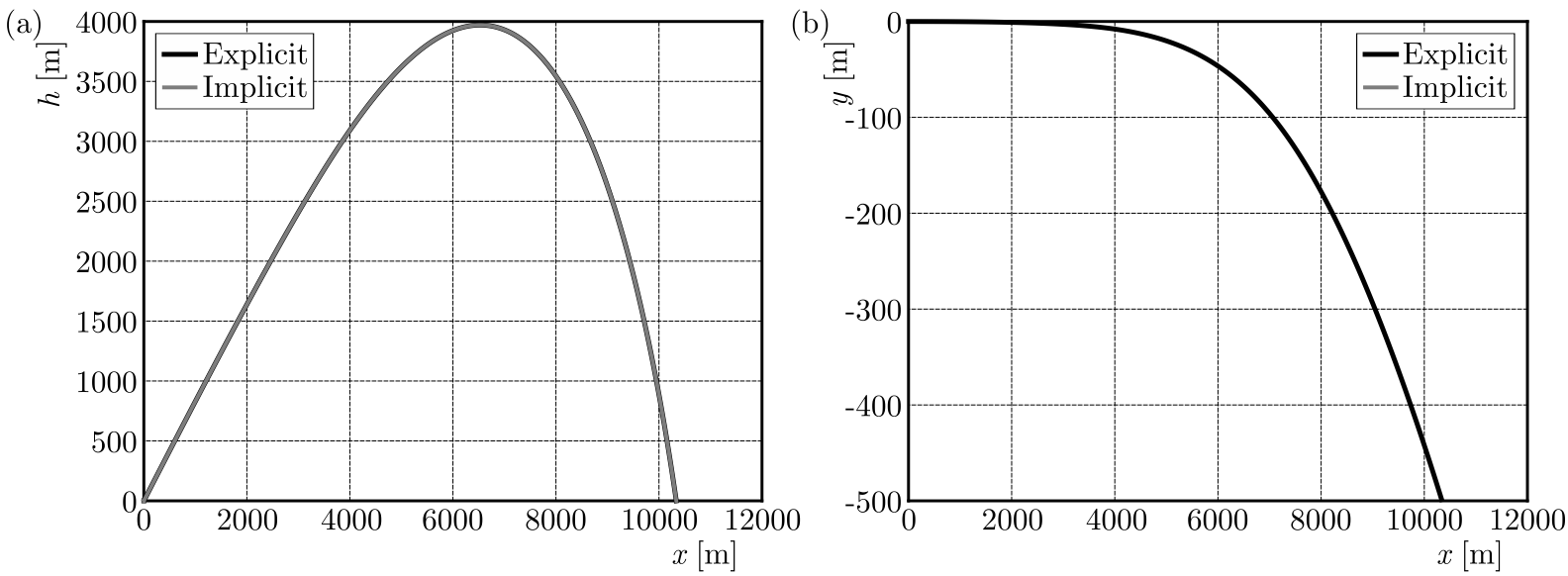

Fig. 2. Projection of the trajectory of $35 \mathrm{~mm}$ TP-T projectile on the vertical plane (a) and horizontal plane (b); standard atmosphere without wind

Tables 1-4 contain information on projectile position and velocity in several chosen moments of time calculated for the implicit and explicit form of the MPMTM. The differences observed in these tables are the result of the precision ${ }^{2}$ used during simulations (1e-12).

\footnotetext{
${ }^{2}$ Tolerance set for the integration method is a measure of the error relative to the size of each solution component. Roughly, it controls the number of correct digits in all solution components MATLAB 2014b Documentation
} 
While comparing the models presented in Section 2, it is important to remember (when the wind velocity is non-zero) that they return projectile velocities in different reference frames:

- explicit model returns velocity in the air-flow ${ }^{3}$ reference system,

- implicit model returns velocity in the the anti-aircraft gun reference system.

Figure 3 visualizes absolute errors of the projectile position and velocity for two forms of the MPMTM.

Table 1. Comparison of the projectile horizontal position ( $x$-coordinate) in chosen moments of time; standard atmosphere without wind

\begin{tabular}{|c|c|c|c|}
\hline $\begin{array}{c}\text { Time of } \\
\text { flight }[\mathrm{s}]\end{array}$ & $\begin{array}{c}x \text {-explicit } \\
{[\mathrm{m}]}\end{array}$ & $\begin{array}{c}x \text {-implicit } \\
{[\mathrm{m}]}\end{array}$ & $\begin{array}{c}\Delta x \\
{[\mathrm{~m}]}\end{array}$ \\
\hline \hline 5 & $2.879740543380384 \mathrm{e}+03$ & $2.879740543380467 \mathrm{e}+03$ & $-8.276401786133647 \mathrm{e}-11$ \\
\hline 10 & $4.283281165179276 \mathrm{e}+03$ & $4.283281165179690 \mathrm{e}+03$ & $-4.138200893066824 \mathrm{e}-10$ \\
\hline 15 & $5.352708930364734 \mathrm{e}+03$ & $5.352708930365055 \mathrm{e}+03$ & $-3.210516297258437 \mathrm{e}-10$ \\
\hline 20 & $6.274635184339581 \mathrm{e}+03$ & $6.274635184339474 \mathrm{e}+03$ & $1.073203748092055 \mathrm{e}-10$ \\
\hline 30 & $7.827993890946567 \mathrm{e}+03$ & $7.827993890945661 \mathrm{e}+03$ & $9.067662176676095 \mathrm{e}-10$ \\
\hline 40 & $9.071956738403202 \mathrm{e}+03$ & $9.071956738401780 \mathrm{e}+03$ & $1.422449713572860 \mathrm{e}-09$ \\
\hline 50 & $1.001379407012815 \mathrm{e}+04$ & $1.001379407012648 \mathrm{e}+04$ & $1.669832272455096 \mathrm{e}-09$ \\
\hline
\end{tabular}

Table 2. Comparison of the projectile horizontal position (y-coordinate) in chosen moments of time; standard atmosphere without wind

\begin{tabular}{|c|c|c|c|}
\hline $\begin{array}{c}\text { Time of } \\
\text { flight }[\mathrm{s}]\end{array}$ & $\begin{array}{c}y \text {-explicit } \\
{[\mathrm{m}]}\end{array}$ & $\begin{array}{c}y \text {-implicit } \\
{[\mathrm{m}]}\end{array}$ & $\begin{array}{c}\Delta y \\
{[\mathrm{~m}]}\end{array}$ \\
\hline \hline 5 & -2.615179706617644 & -2.615179706628132 & $1.048805486902893 \mathrm{e}-11$ \\
\hline 10 & -10.437812368269643 & -10.437812368304497 & $3.485389754587231 \mathrm{e}-11$ \\
\hline 15 & -27.482113983932305 & -27.482113983970038 & $3.773337198254012 \mathrm{e}-11$ \\
\hline 20 & -57.329128551977114 & -57.329128551940180 & $-3.693401140481001 \mathrm{e}-11$ \\
\hline 30 & $-1.609880120207460 \mathrm{e}+02$ & $-1.609880120205749 \mathrm{e}+02$ & $-1.710418473521713 \mathrm{e}-10$ \\
\hline 40 & $-3.035886033713625 \mathrm{e}+02$ & $-3.035886033711299 \mathrm{e}+02$ & $-2.325464265595656 \mathrm{e}-10$ \\
\hline 50 & $-4.443484747573776 \mathrm{e}+02$ & $-4.443484747571376 \mathrm{e}+02$ & $-2.399360710114706 \mathrm{e}-10$ \\
\hline
\end{tabular}

Table 3. Comparison of the projectile vertical $h$-coordinate in chosen moments of time; standard atmosphere without wind

\begin{tabular}{|c|c|c|c|}
\hline $\begin{array}{c}\text { Time of } \\
\text { flight }[\mathrm{s}]\end{array}$ & $\begin{array}{c}h \text {-explicit } \\
{[\mathrm{m}]}\end{array}$ & $\begin{array}{c}h \text {-implicit } \\
{[\mathrm{m}]}\end{array}$ & $\begin{array}{c}\Delta h \\
{[\mathrm{~m}]}\end{array}$ \\
\hline \hline 5 & $2.318321798332399 \mathrm{e}+03$ & $2.318321798332298 \mathrm{e}+03$ & $1.009539118967950 \mathrm{e}-10$ \\
\hline 10 & $3.260802764803827 \mathrm{e}+03$ & $3.260802764803513 \mathrm{e}+03$ & $3.137756721116602 \mathrm{e}-10$ \\
\hline 15 & $3.756859479068482 \mathrm{e}+03$ & $3.756859479067962 \mathrm{e}+03$ & $5.197762220632285 \mathrm{e}-10$ \\
\hline 20 & $3.959477637219192 \mathrm{e}+03$ & $3.959477637218932 \mathrm{e}+03$ & $2.596607373561710 \mathrm{e}-10$ \\
\hline 30 & $3.644341649231496 \mathrm{e}+03$ & $3.644341649231876 \mathrm{e}+03$ & $-3.801687853410840 \mathrm{e}-10$ \\
\hline 40 & $2.533030738575992 \mathrm{e}+03$ & $2.533030738576817 \mathrm{e}+03$ & $-8.244569471571594 \mathrm{e}-10$ \\
\hline 50 & $8.539543121131945 \mathrm{e}+02$ & $8.539543121141693 \mathrm{e}+02$ & $-9.747509466251358 \mathrm{e}-10$ \\
\hline
\end{tabular}

\footnotetext{
${ }^{3}$ Air-frame reference system has been chosen as the most convenient for calculations
} 
Table 4. Comparison of the projectile velocity in chosen moments of time; standard atmosphere without wind

\begin{tabular}{|c|c|c|c|}
\hline $\begin{array}{c}\text { Time of } \\
\text { flight }[\mathrm{s}]\end{array}$ & $\begin{array}{c}v \text {-explicit } \\
{[\mathrm{m} / \mathrm{s}]}\end{array}$ & $\begin{array}{c}v \text {-implicit } \\
{[\mathrm{m} / \mathrm{s}]}\end{array}$ & $\begin{array}{c}\Delta v \\
{[\mathrm{~m} / \mathrm{s}]}\end{array}$ \\
\hline \hline 5 & $4.582123481454996 \mathrm{e}+02$ & $4.582123481455023 \mathrm{e}+02$ & $-2.671640686457977 \mathrm{e}-12$ \\
\hline 10 & $2.694330549712324 \mathrm{e}+02$ & $2.694330549712641 \mathrm{e}+02$ & $-3.177547114319168 \mathrm{e}-11$ \\
\hline 15 & $2.084609346355481 \mathrm{e}+02$ & $2.084609346355003 \mathrm{e}+02$ & $4.780531526193954 \mathrm{e}-11$ \\
\hline 20 & $1.738563395829701 \mathrm{e}+02$ & $1.738563395828820 \mathrm{e}+02$ & $8.813572094368283 \mathrm{e}-11$ \\
\hline 30 & $1.584999648980999 \mathrm{e}+02$ & $1.584999648980213 \mathrm{e}+02$ & $7.861444828449748 \mathrm{e}-11$ \\
\hline 40 & $1.814453824749712 \mathrm{e}+02$ & $1.814453824749252 \mathrm{e}+02$ & $4.595790414896328 \mathrm{e}-11$ \\
\hline 50 & $2.034057467881448 \mathrm{e}+02$ & $2.034057467881248 \mathrm{e}+02$ & $1.995204002014361 \mathrm{e}-11$ \\
\hline
\end{tabular}

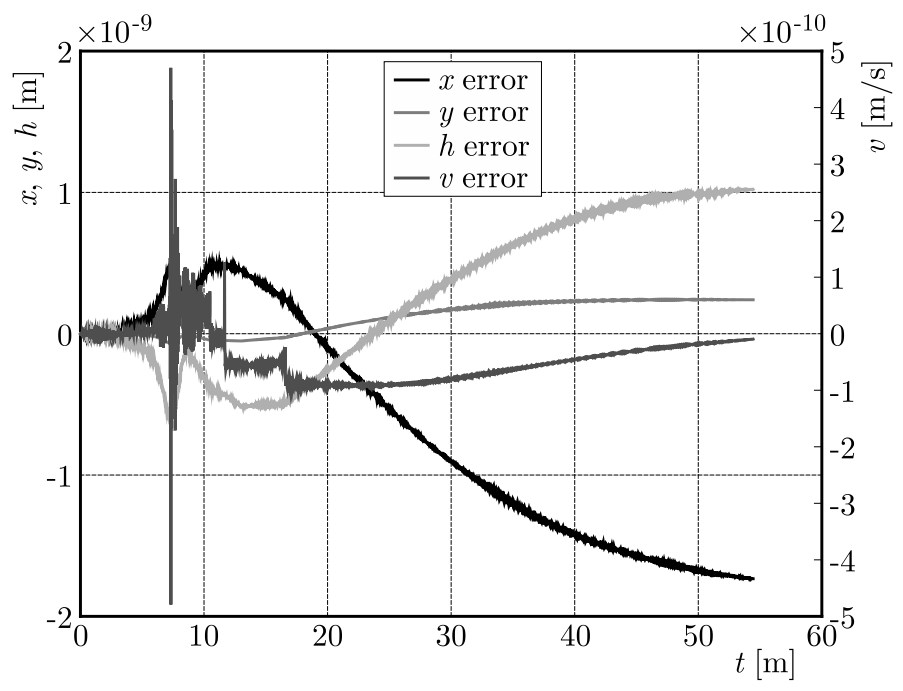

Fig. 3. Absolute differences of projectile position and velocity as a function of time for the explicit and implicit form of the MPMTM; standard atmosphere, no wind

(a)

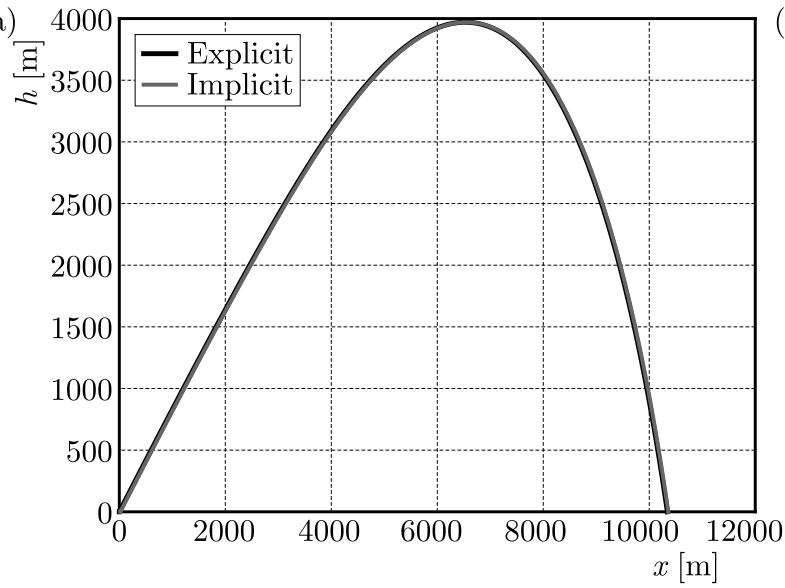

(b)

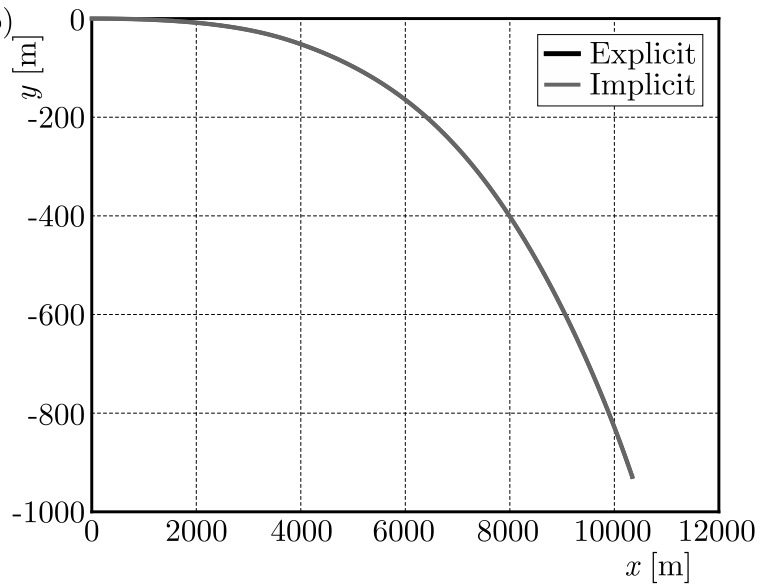

Fig. 4. Projection of the trajectory of $35 \mathrm{~mm}$ TP-T projectile on the vertical plane (a) and horizontal plane (b); standard atmosphere, cross wind $-10 \mathrm{~m} / \mathrm{s}$ 


\subsection{Results for standard atmospheric conditions with cross wind}

Figures $4 \mathrm{a}$ and $4 \mathrm{~b}$ present trajectory projections in the case of the presence of homogeneous cross wind blowing with the velocity $-10 \mathrm{~m} / \mathrm{s}$ (other conditions remain the same as in the previous case). Aside from figures, we also publish tables with the results of integration of the differential equations for both forms of the MPMTM (Tables 5 to 8). Absolute differences between respective values are shown in the tables as well as in Fig. 5.

Table 5. Comparison of the projectile horizontal position ( $x$-coordinate) in chosen moments of time; standard atmosphere, homogeneous cross wind $(-10 \mathrm{~m} / \mathrm{s})$

\begin{tabular}{|c|c|c|c|}
\hline $\begin{array}{c}\text { Time of } \\
\text { flight }[\mathrm{s}]\end{array}$ & $\begin{array}{c}x \text {-explicit } \\
{[\mathrm{m}]}\end{array}$ & $\begin{array}{c}x \text {-implicit } \\
{[\mathrm{m}]}\end{array}$ & $\begin{array}{c}\Delta x \\
{[\mathrm{~m}]}\end{array}$ \\
\hline \hline 5 & $2.879759177098334 \mathrm{e}+03$ & $2.879759177098053 \mathrm{e}+03$ & $-2.810338628478348 \mathrm{e}-10$ \\
\hline 10 & $4.283361832919431 \mathrm{e}+03$ & $4.283361832918131 \mathrm{e}+03$ & $-1.300577423535287 \mathrm{e}-09$ \\
\hline 15 & $5.352944802665610 \mathrm{e}+03$ & $5.352944802661354 \mathrm{e}+03$ & $-4.256435204297304 \mathrm{e}-09$ \\
\hline 20 & $6.275169112336884 \mathrm{e}+03$ & $6.275169112329893 \mathrm{e}+03$ & $-6.990376277826726 \mathrm{e}-09$ \\
\hline 30 & $7.829612391519409 \mathrm{e}+03$ & $7.829612391508746 \mathrm{e}+03$ & $-1.066291588358581 \mathrm{e}-08$ \\
\hline 40 & $9.075093437693744 \mathrm{e}+03$ & $9.075093437681275 \mathrm{e}+03$ & $-1.246917236130685 \mathrm{e}-08$ \\
\hline 50 & $1.001843598545247 \mathrm{e}+04$ & $1.001843598543946 \mathrm{e}+04$ & $-1.301486918237060 \mathrm{e}-08$ \\
\hline
\end{tabular}

Table 6. Comparison of the projectile horizontal position ( $y$-coordinate) in chosen moments of time; standard atmosphere, homogeneous cross wind $(-10 \mathrm{~m} / \mathrm{s})$

\begin{tabular}{|c|c|c|c|}
\hline $\begin{array}{c}\text { Time of } \\
\text { flight }[\mathrm{s}]\end{array}$ & $\begin{array}{c}y \text {-explicit } \\
{[\mathrm{m}]}\end{array}$ & $\begin{array}{c}y \text {-implicit } \\
{[\mathrm{m}]}\end{array}$ & $\begin{array}{c}\Delta y \\
{[\mathrm{~m}]}\end{array}$ \\
\hline \hline 5 & -20.786332880295095 & -20.786332880260023 & $3.507238943711855 \mathrm{e}-11$ \\
\hline 10 & -63.095834383862190 & -63.095834383657966 & $2.042241931121680 \mathrm{e}-10$ \\
\hline 15 & $-1.183192056414523 \mathrm{e}+02$ & $-1.183192056408177 \mathrm{e}+02$ & $6.345430847431999 \mathrm{e}-10$ \\
\hline 20 & $-1.879744883329794 \mathrm{e}+02$ & $-1.879744883319200 \mathrm{e}+02$ & $1.059447640727740 \mathrm{e}-09$ \\
\hline 30 & $-3.744560742377584 \mathrm{e}+02$ & $-3.744560742362193 \mathrm{e}+02$ & $1.539149252494099 \mathrm{e}-09$ \\
\hline 40 & $-6.032941561003266 \mathrm{e}+02$ & $-6.032941560987131 \mathrm{e}+02$ & $1.613557287782896 \mathrm{e}-09$ \\
\hline 50 & $-8.336302688008207 \mathrm{e}+02$ & $-8.336302687993701 \mathrm{e}+02$ & $1.450530362490099 \mathrm{e}-09$ \\
\hline
\end{tabular}

Table 7. Comparison of the projectile vertical $h$-coordinate in chosen moments of time; standard atmosphere, homogeneous cross wind $(-10 \mathrm{~m} / \mathrm{s})$

\begin{tabular}{|c|c|c|c|}
\hline $\begin{array}{c}\text { Time of } \\
\text { flight }[\mathrm{s}]\end{array}$ & $\begin{array}{c}h \text {-explicit }] \\
{[\mathrm{m}]}\end{array}$ & $\begin{array}{c}h \text {-implicit } \\
{[\mathrm{m}]}\end{array}$ & $\begin{array}{c}\Delta h \\
{[\mathrm{~m}]}\end{array}$ \\
\hline \hline 5 & $2.318313372013739 \mathrm{e}+03$ & $2.318313372014125 \mathrm{e}+03$ & $3.865352482534945 \mathrm{e}-10$ \\
\hline 10 & $3.260776306927196 \mathrm{e}+03$ & $3.260776306929160 \mathrm{e}+03$ & $1.963144313776866 \mathrm{e}-09$ \\
\hline 15 & $3.756809955845482 \mathrm{e}+03$ & $3.756809955850505 \mathrm{e}+03$ & $5.022684490540996 \mathrm{e}-09$ \\
\hline 20 & $3.959406864678785 \mathrm{e}+03$ & $3.959406864686925 \mathrm{e}+03$ & $8.139977580867708 \mathrm{e}-09$ \\
\hline 30 & $3.644234110531493 \mathrm{e}+03$ & $3.644234110544769 \mathrm{e}+03$ & $1.327543941442855 \mathrm{e}-08$ \\
\hline 40 & $2.532897496773589 \mathrm{e}+03$ & $2.532897496790511 \mathrm{e}+03$ & $1.692160367383622 \mathrm{e}-08$ \\
\hline 50 & $8.538100257788867 \mathrm{e}+02$ & $8.538100257975424 \mathrm{e}+02$ & $1.865566900960403 \mathrm{e}-08$ \\
\hline
\end{tabular}


Table 8. Comparison of the projectile velocity in chosen moments of time; standard atmosphere, homogeneous cross wind $(-10 \mathrm{~m} / \mathrm{s})$

\begin{tabular}{|c|c|c|c|}
\hline $\begin{array}{c}\text { Time of } \\
\text { flight }[\mathrm{s}]\end{array}$ & $\begin{array}{c}v \text {-explicit } \\
{[\mathrm{m} / \mathrm{s}]}\end{array}$ & $\begin{array}{c}v \text {-implicit } \\
{[\mathrm{m} / \mathrm{s}]}\end{array}$ & $\begin{array}{c}\Delta v \\
{[\mathrm{~m} / \mathrm{s}]}\end{array}$ \\
\hline \hline 5 & $4.582266925378976 \mathrm{e}+02$ & $4.582266925378934 \mathrm{e}+02$ & $-4.206412995699793 \mathrm{e}-12$ \\
\hline 10 & $2.694372225018485 \mathrm{e}+02$ & $2.694372225017880 \mathrm{e}+02$ & $-6.048139766789973 \mathrm{e}-11$ \\
\hline 15 & $2.084647377666492 \mathrm{e}+02$ & $2.084647377662564 \mathrm{e}+02$ & $-3.927880243281834 \mathrm{e}-10$ \\
\hline 20 & $1.738602908045667 \mathrm{e}+02$ & $1.738602908041290 \mathrm{e}+02$ & $-4.376374818093609 \mathrm{e}-10$ \\
\hline 30 & $1.585036690668833 \mathrm{e}+02$ & $1.585036690664340 \mathrm{e}+02$ & $-4.492619609663962 \mathrm{e}-10$ \\
\hline 40 & $1.814475179841104 \mathrm{e}+02$ & $1.814475179838305 \mathrm{e}+02$ & $-2.798401510517579 \mathrm{e}-10$ \\
\hline 50 & $2.034062035223828 \mathrm{e}+02$ & $2.034062035223219 \mathrm{e}+02$ & $-6.087930159992538 \mathrm{e}-11$ \\
\hline
\end{tabular}

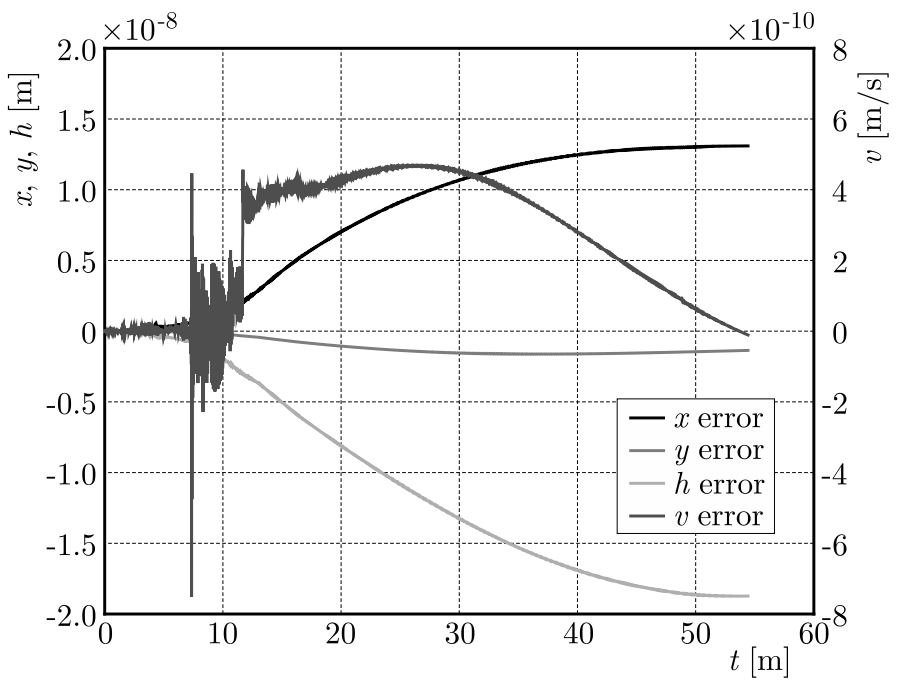

Fig. 5. Absolute differences of projectile position and velocity as a function of time for the explicit and implicit form of the MPMTM; standard atmosphere, homogeneous crosswind $(-10 \mathrm{~m} / \mathrm{s})$

\subsection{Results for standard atmospheric conditions with tail wind}

Figures $6 \mathrm{a}$ and $6 \mathrm{~b}$ present trajectories projections in the case of the presence of homogeneous tail wind blowing with the velocity $10 \mathrm{~m} / \mathrm{s}$ (other conditions remain the same as described in 4.1).

(a)

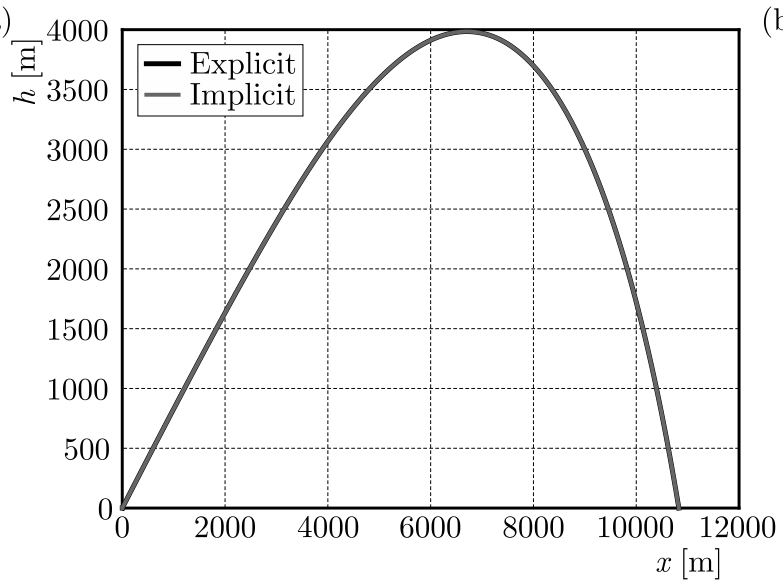

(b)

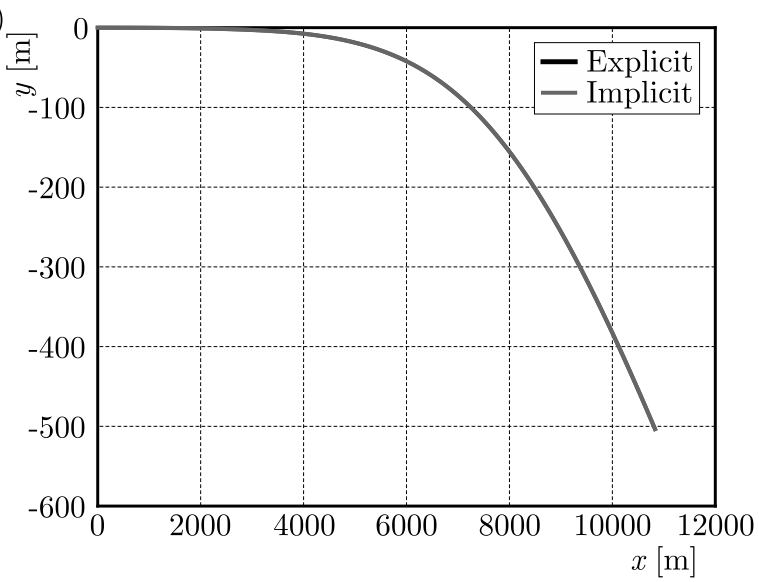

Fig. 6. Projection of the trajectory on the vertical plane (a) and horizontal plane (b); standard atmosphere, tail wind $10 \mathrm{~m} / \mathrm{s}$ 
Table 9. Comparison of the projectile horizontal position ( $x$-coordinate) in chosen moments of time; standard atmosphere, homogeneous tail wind $(10 \mathrm{~m} / \mathrm{s})$

\begin{tabular}{|c|c|c|c|}
\hline $\begin{array}{c}\text { Time of } \\
\text { flight }[\mathrm{s}]\end{array}$ & $\begin{array}{c}x \text {-explicit } \\
{[\mathrm{m}]}\end{array}$ & $\begin{array}{c}x \text {-implicit } \\
{[\mathrm{m}]}\end{array}$ & $\begin{array}{c}\Delta x \\
{[\mathrm{~m}]}\end{array}$ \\
\hline \hline 5 & $2.899745751481406 \mathrm{e}+03$ & $2.899745751481390 \mathrm{e}+03$ & $1.637090463191271 \mathrm{e}-11$ \\
\hline 10 & $4.342170882757351 \mathrm{e}+03$ & $4.342170882757300 \mathrm{e}+03$ & $5.093170329928398 \mathrm{e}-11$ \\
\hline 15 & $5.455738001516948 \mathrm{e}+03$ & $5.455738001517138 \mathrm{e}+03$ & $-1.891748979687691 \mathrm{e}-10$ \\
\hline 20 & $6.423191936662845 \mathrm{e}+03$ & $6.423191936663049 \mathrm{e}+03$ & $-2.037268131971359 \mathrm{e}-10$ \\
\hline 30 & $8.070359880147351 \mathrm{e}+03$ & $8.070359880147523 \mathrm{e}+03$ & $-1.718944986350834 \mathrm{e}-10$ \\
\hline 40 & $9.410976469705320 \mathrm{e}+03$ & $9.410976469705542 \mathrm{e}+03$ & $-2.219167072325945 \mathrm{e}-10$ \\
\hline 50 & $1.045149163528715 \mathrm{e}+04$ & $1.045149163528757 \mathrm{e}+04$ & $-4.165485734120011 \mathrm{e}-10$ \\
\hline
\end{tabular}

Table 10. Comparison of the projectile horizontal position (y-coordinate) in chosen moments of time; standard atmosphere, homogeneous tail wind $(10 \mathrm{~m} / \mathrm{s})$

\begin{tabular}{|c|c|c|c|}
\hline $\begin{array}{c}\text { Time of } \\
\text { flight }[\mathrm{s}]\end{array}$ & $\begin{array}{c}y \text {-explicit } \\
{[\mathrm{m}]}\end{array}$ & $\begin{array}{c}y \text {-implicit } \\
{[\mathrm{m}]}\end{array}$ & $\begin{array}{c}\Delta y \\
{[\mathrm{~m}]}\end{array}$ \\
\hline \hline 5 & -2.614508424916781 & -2.614508424914710 & $-2.071232074740692 \mathrm{e}-12$ \\
\hline 10 & -10.447910913790327 & -10.447910913786751 & $-3.575806317712704 \mathrm{e}-12$ \\
\hline 15 & -27.533351120232908 & -27.533351120240553 & $7.645439836778678 \mathrm{e}-12$ \\
\hline 20 & -57.473911630279034 & -57.473911630223405 & $-5.562839078265824 \mathrm{e}-11$ \\
\hline 30 & $-1.616578103374976 \mathrm{e}+02$ & $-1.616578103373247 \mathrm{e}+02$ & $-1.728892584651476 \mathrm{e}-10$ \\
\hline 40 & $-3.052317376261908 \mathrm{e}+02$ & $-3.052317376259557 \mathrm{e}+02$ & $-2.351043804083020 \mathrm{e}-10$ \\
\hline 50 & $-4.470705154062585 \mathrm{e}+02$ & $-4.470705154060170 \mathrm{e}+02$ & $-2.415276867395733 \mathrm{e}-10$ \\
\hline
\end{tabular}

Table 11. Comparison of the projectile vertical $h$-coordinate in chosen moments of time; standard atmosphere, homogeneous tail wind $(10 \mathrm{~m} / \mathrm{s})$

\begin{tabular}{|c|c|c|c|}
\hline $\begin{array}{c}\text { Time of } \\
\text { flight }[\mathrm{s}]\end{array}$ & $\begin{array}{c}h \text {-explicit } \\
{[\mathrm{m}]}\end{array}$ & $\begin{array}{c}h \text {-implicit } \\
{[\mathrm{m}]}\end{array}$ & $\begin{array}{c}\Delta h \\
{[\mathrm{~m}]}\end{array}$ \\
\hline \hline 5 & $2.319843392772728 \mathrm{e}+03$ & $2.319843392772747 \mathrm{e}+03$ & $-1.955413608811796 \mathrm{e}-11$ \\
\hline 10 & $3.265607481624752 \mathrm{e}+03$ & $3.265607481624821 \mathrm{e}+03$ & $-6.821210263296962 \mathrm{e}-11$ \\
\hline 15 & $3.765857597754436 \mathrm{e}+03$ & $3.765857597754508 \mathrm{e}+03$ & $-7.230482879094780 \mathrm{e}-11$ \\
\hline 20 & $3.972340990237719 \mathrm{e}+03$ & $3.972340990238237 \mathrm{e}+03$ & $-5.184119800105691 \mathrm{e}-10$ \\
\hline 30 & $3.663900131717957 \mathrm{e}+03$ & $3.663900131719271 \mathrm{e}+03$ & $-1.313765096710995 \mathrm{e}-09$ \\
\hline 40 & $2.557278531390514 \mathrm{e}+03$ & $2.557278531392392 \mathrm{e}+03$ & $-1.878106559161097 \mathrm{e}-09$ \\
\hline 50 & $8.802228281796221 \mathrm{e}+02$ & $8.802228281817677 \mathrm{e}+02$ & $-2.145611688320059 \mathrm{e}-09$ \\
\hline
\end{tabular}

Table 12. Comparison of the projectile velocity in chosen moments of time; standard atmosphere, homogeneous tail wind $(10 \mathrm{~m} / \mathrm{s})$

\begin{tabular}{|c|c|c|c|}
\hline $\begin{array}{c}\text { Time of } \\
\text { flight }[\mathrm{s}]\end{array}$ & $\begin{array}{c}v \text {-explicit } \\
{[\mathrm{m} / \mathrm{s}]}\end{array}$ & $\begin{array}{c}v \text {-implicit } \\
{[\mathrm{m} / \mathrm{s}]}\end{array}$ & $\begin{array}{c}\Delta v \\
{[\mathrm{~m} / \mathrm{s}]}\end{array}$ \\
\hline \hline 5 & $4.556196037618452 \mathrm{e}+02$ & $4.556196037618386 \mathrm{e}+02$ & $6.593836587853730 \mathrm{e}-12$ \\
\hline 10 & $2.686771069413229 \mathrm{e}+02$ & $2.686771069413665 \mathrm{e}+02$ & $-4.354205884737894 \mathrm{e}-11$ \\
\hline 15 & $2.077692047266052 \mathrm{e}+02$ & $2.077692047266444 \mathrm{e}+02$ & $-3.922195901395753 \mathrm{e}-11$ \\
\hline 20 & $1.731362186963469 \mathrm{e}+02$ & $1.731362186963497 \mathrm{e}+02$ & $-2.728484105318785 \mathrm{e}-12$ \\
\hline 30 & $1.578228372701631 \mathrm{e}+02$ & $1.578228372701328 \mathrm{e}+02$ & $3.029754225281067 \mathrm{e}-11$ \\
\hline 40 & $1.810541039539512 \mathrm{e}+02$ & $1.810541039539235 \mathrm{e}+02$ & $2.768274498521350 \mathrm{e}-11$ \\
\hline 50 & $2.033211141640507 \mathrm{e}+02$ & $2.033211141640362 \mathrm{e}+02$ & $1.458033693779726 \mathrm{e}-11$ \\
\hline
\end{tabular}


Tables 9-12 present exemplary results of the projectile trajectory calculations using both forms of the MPMTM. Absolute differences between the respective values are shown in the tables as well as in Fig. 7.

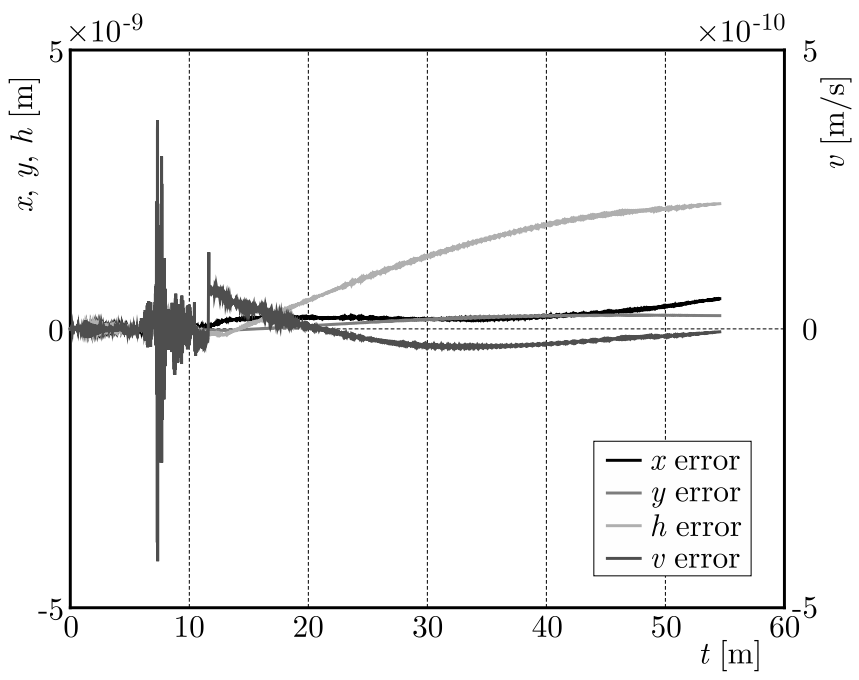

Fig. 7. Absolute differences of projectile position and velocity as a function of time for the explicit and implicit form of the MPM model; standard atmosphere, homogeneous tail wind $(10 \mathrm{~m} / \mathrm{s})$

\subsection{Calculation time}

Another aspect that we have taken under consideration is the runtime needed for the necessary computations. Figure $8 \mathrm{~b}$ shows the time needed for trajectory generation for different elevation angles: 10 to 710 mil with the interval of 20 mils. As mentioned before, the differential equations have been integrated using the non-stiff fourth-order Runge-Kutta solver ode45. The stopping condition for numerical integration was the moment when the projectile reached the point of fall ${ }^{4}$.

(a)

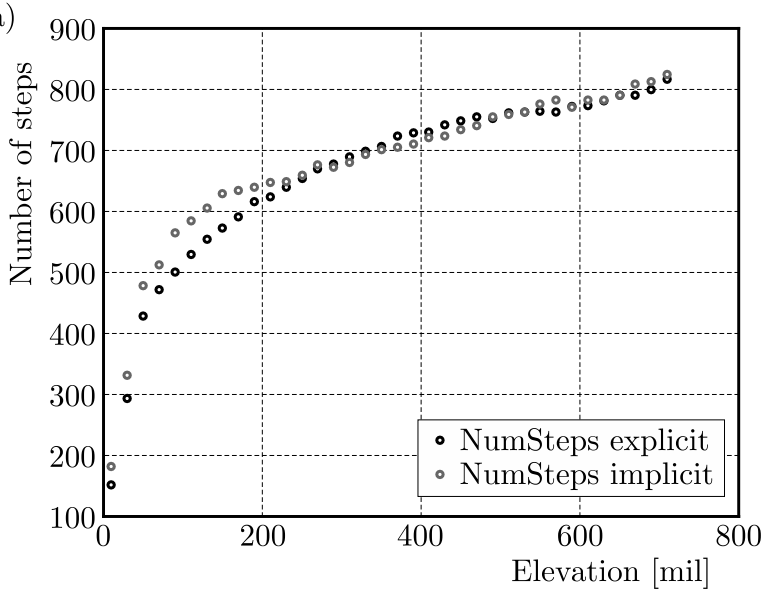

(b)

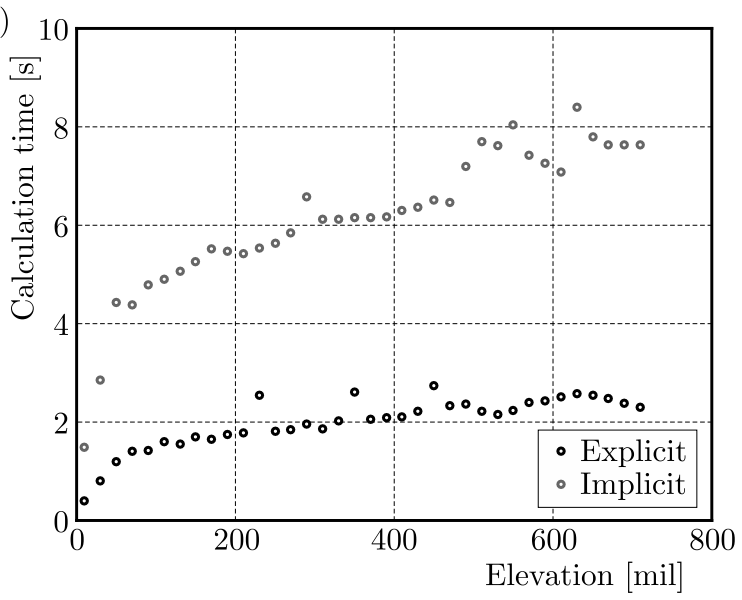

Fig. 8. (a) Number of steps for the implicit and explicit forms of the MPMTM using the ode45 solver; (b) comparison of the trajectory calculation time for both forms of the MPMTM

As it can be seen, the explicit model needs much less time (up to 4 times less) to calculate the trajectory. Figure 8a shows statistics drawn from the ode45 solver - the aggregate number of steps (both successful and failed). One can easily notice that the solver needs much less time

\footnotetext{
${ }^{4}$ The point of intersection between the trajectory and the weapon level surface STANAG 4119, 2007
} 
for the explicit form of MPMTM despite a similar number of steps and function evaluations (Fig. 8a).

\section{Conclusions}

The aim of this paper is to compare an implicit form of the MPMTM with the explicit one, which was derived by Baranowski et al. (2016). As it is shown in Section 4, simulations of the $35 \mathrm{~mm}$ TP-T projectile trajectory gives the same results for both model forms in the following cases:

- standard atmosphere without the presence of wind within the whole integration interval;

- standard atmosphere with homogeneous side wind within the whole integration interval;

- standard atmosphere with homogeneous tail wind within the whole integration interval.

Furthermore, it is shown that the explicit MPMTM can integrate differential equations of motion up to 4 times faster than the implicit form, which is solely attributed to the fact that the explicit analytic formula for the yaw of repose has been derived. This freed us from the cost of unnecessary FLOPS needed to approximate $\alpha_{e}$. The great reduction of runtime in the explicit model is of great importance and can significantly enhance the process of aerodynamic coefficients identification. This process, based on ammo data and firing tables (ground and anti-aircraft), needs time consuming calculations, i.e. finding local minima of complicated functions (given by ODEs) in multi-dimensional parameter spaces, with the impossible aim of finding the global minimum the ideal fit. Moreover, an explicit formula does not have convergence issues which might appear in the implicit method. It seems justified to apply the explicit form of the MPMTM to the identification process of aerodynamic coefficients on which we will focus in our future work.

Acknowledgement

This paper was created as a part of the development project No. OROB 004603001 financed by Polish National Centre for Research and Development in the period between 2012 and 2015.

\section{References}

1. Baranowski L., 2013, Feasibility analysis of the modified point mass trajectory model for the need of ground artillery fire control systems, Journal of Theoretical and Applied Mechanics, 51, 3, $511-522$

2. Baranowski L., FurmaneK W., 2013, The problem of validation of the trajectory model of $35 \mathrm{~mm}$ calibre projectile TP-T in the normal conditions (in Polish), Problemy Techniki Uzbrojenia, 125, 35-44

3. Baranowski L., Gadomski B., Majewski P., Szymonik J., 2016, Explicit "ballistic M-model": a refinement of the implicit "modified point mass trajectory model", Bulletin of the Polish Academy of Sciences - Technical Sciences, 64, 1, 81-89

4. Coleman N., May R., Neelakandan M., Papanagopoulos G., Udomkesmalee S., Lin C.F., Politopoulos A., 2003, Fire control solution using robust MET data extraction and impact point prediction, 4th International Conference on Control and Automation ICCA'03, Montreal, $770-774$

5. ISO 2533, 1975, The ISO Standard Atmosphere, U.S. Government Printing Office, Washington, D.C.

6. Koruba Z., Dziopa Z., Krzysztofik I., 2010, Dynamics and control of a gyroscope-stabilized platform in a self-propelled anti-aircraft system, Journal of Theoretical and Applied Mechanics, 48, $1,5-26$ 
7. Kowaleczko G., Żyluk A., 2009, Influence of atmospheric turbulence on bomb release, Journal of Theoretical and Applied Mechanics, 47, 1, 69-90

8. ŁADYŻYŃSKA-KOZDRAŚ E., 2012, Modeling and numerical simulation of unmanned aircraft vehicle restricted by non-holonomic constraints, Journal of Theoretical and Applied Mechanics, 50, 1, 251-268

9. Lieske R.F., Reiter M.L., 1966, Equations of Motion for a Modified point Mass Trajectory, U.S. Army Ballistic Research Laboratory, Report No. 1314

10. MATLAB 2014b Documentation

11. McCoy R.L., 1999, Modern Exterior Ballistics. The Launch and Flight Dynamics of Symmetric Projectiles, Schiffer Publishing

12. Pope R.L., 1978, The Analysis of Trajectory and Solar Aspect Angle Records of Shell Flights. Theory and Computer Programs, Department of Defence, Defence Science and Technology Organistaion, Weapons Systems Research Laboratory

13. Shanks D., Walton T.S., 1957, A New General Formula for Representing the Drag on a Missile Over the Entire Range of Mach Number, NAVORD Report 3634, May

14. STANAG 4119, 2007, Adoption of a Standard Cannon Artillery Firing Table Format, Ed. 2

15. STANAG 4355, 2009, The Modified Point Mass and Five Degrees of Freedom Trajectory Models, Ed. 3

Manuscript received July 22, 2015; accepted for print February 18, 2016 